\title{
Second Language Acquisition of Complex Structures: The Case of English Restrictive Relative Clauses
}

\author{
Alexandra I. Prentza \\ Department of Theoretical and Applied Linguistics, School of English, Aristotle University of Thessaloniki, 54 124, \\ Thessaloniki, Greece \\ Email: prentzal@gmail.gr
}

\begin{abstract}
This paper examines the formation of Restrictive Relative Clauses (RRC) in Greek and English and investigates the acquisition of English RRCs by advanced Greek learners. On the assumption that L1 Greek and L2 English exhibit parametrically different choices as regards RRC formation which are associated with abstract syntactic features, the current experiment addresses the question of whether parameter resetting is possible in adult L2 acquisition. The results have shown that non-native speakers (NNSs) fared significantly less successfully than native speakers (NSs) in the relevant grammaticality judgement task. The conclusion is that advanced Greek learners fail to acquire the feature specification of the English relative $\mathrm{C}$. The obtained data lends additional support to recent $\mathrm{L} 2$ theories which maintain that syntactic divergence between $\mathrm{L} 1$ and $\mathrm{L} 2$ is associated with prolonged acquisitional problems.
\end{abstract}

Index Terms - second language acquisition, restrictive relative clauses, syntax, formal features

\section{INTRODUCTION}

English Restrictive Relative Clauses constitute complex syntactic structures which Greek second language (L2) learners are exposed to in post-intermediate level of proficiency. Although, like non-RRCs, they modify a noun and specify its reference (Haegeman \& Gueron, 1999), RRCs are different at a phonological, semantic and syntactic level: they are not separated from the rest of the sentence through intonation (pause) or punctuation (commas), they convey information which is central to the information of the whole construction (Huddleston, 1993) and finally, they are modifiers, unlike non-RRCs which have no syntactic relation to their antecedent (Fabb, 1990). Compare (1a) and (1b):

(1) a. Maria, who has a Ph.D. in European Integration, is now unemployed. (non-RRC)

b. Tonight I will wear the dress which I bought yesterday.

(RRC)

Additionally, as will be discussed later in detail, English RRCs are different than Greek RRCs in terms of syntactic features and formation. However, in no course book either published by Greek or English publishing houses are the particular characteristics of these clauses which differentiate them from the equivalent Greek structures presented to Greek learners. Moreover, to the best of my knowledge, most foreign language teachers fail to incorporate this point in their teaching, since such an approach bears on a more theoretical background, that of second language acquisition syntax, which they may lack.

The present papers aims at presenting the differences between Greek and English RRCs as well as at exploring the L2 acquisition of these structures by advanced Greek learners. As regards the exploration of RRC L2 acquisition, empirical evidence will be provided which shows its problematic nature, namely that (ultimate) attainment of the permutation under question is difficult if not unfeasible for L2 learners whose native language (L1) syntactically differs in this respect.

\section{THEORETICAL FRAMEWORK}

This paper will adopt a Universal Grammar (UG) approach (Chomsky, 1981; 1986a; 1995) to second language acquisition (SLA), namely that the construction of L2 grammars abides by the same universal principles, i.e. the fundamental and invariant sets of rules shared by all human languages, that guide L1 acquisition. On the other hand, the structural diversity among human languages is represented by the concept of parameters which, unlike UG principles have to be fixed by experience upon exposure to a linguistic system. According to minimalist assumptions on the architecture of the language system parametric differences between languages, or in other words cross-linguistic variation, have been associated with abstract syntactic features which differ between L1 and L2. Moreover, much recent research has provided convergent evidence that when L1 and L2 differ with respect to formal syntactic features, ultimate attainment of the involved structure(s) is impossible the reason being that L1 influences L2 representations even at advanced stages of proficiency though L1 parametric options (see Tsimpli \& Roussou, 1991; Smith \& Tsimpli, 
1995; Hawkins \& Chan, 1997; Beck, 1998; Hawkins \& Hattori, 2006; Tsimpli \& Dimitrakopoulou, 2007; Prentza \& Tsimpli, in press).

\section{A. Subjacency: A UG Principle and Proposed Parameters}

English RRCs have been traditionally assumed to involve the movement of a wh-word to the specifier position of the Complementizer Phrase (CP), i.e. in Spec-CP position, in the embedded clause (Chomsky, 1986b) Since wh-movement is involved, then locality constraints on movement apply in these structures and the UG principle of subjacency is considered relevant. The principle of subjacency is usually expressed along the following lines:

(2) Subjacency

A constituent may cross only one bounding node in a single movement.

Given that for English Noun Phrase (NP) and Inflection Phrase (IP) are bounding nodes (or 'domains), when an NP takes a clausal complement, extraction of a wh-word from that clausal complement is ungrammatical, as it violates subjacency:

(\# indicates the bounding nodes crossed which induce subjacency violations)

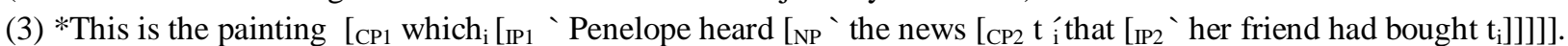

Wh-extraction out of a clause headed by a wh-phrase, a wh-island as it is called, also gives rise to subjacency violations:

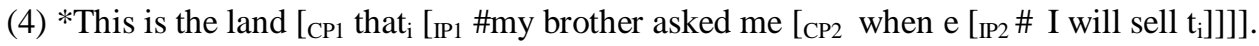

Other constructions that induce subjacency violations are relative clauses and complex (or sentential) subjects. Notice crucially that since subjacency is a constraint on movement, in non-movement structures this principle does not apply.

In early work it was proposed that different constituents could count as boundary nodes for the principle of subjacency cross-linguistically. In this vein, Rizzi (1982) proposed that bounding nodes are parameterized. While it was stipulated that for English, NP and IP are bounding nodes, Rizzi suggested that for Italian bounding nodes would be NP and CP.

In later work additional proposals were formulated, one of them being that the overt or not movement of whoperators is parameterized. Related to the assumption that English RRC formation requires a wh-word to move from an argument position in the embedded clause to the non-argument Spec-CP position is the assumption that this movement is triggered by a 'strong' [wh] feature on the relative C for the purposes of 'checking', as Chomsky (1995) proposes. According to Checking Theory functional heads like $\mathrm{C}$ dominate a cluster of abstract grammatical features which may be strong or weak and which must be checked by a matching lexical item. Wh-movement is motivated by the checking of abstract specifier features of a functional head. Specifier features must be checked by a maximal projection in a specifier head-relation. While strong features must be checked by overt movement, weak features must be checked by covert movement at the symbolic system of Logical Form ${ }^{1}$ (LF). In other words, the morphological strength of the [wh] feature on $\mathrm{C}$ is related to the level of application of wh-movement cross-linguistically. Since in languages like English overt movement is necessary but in languages like Japanese or Chinese it is not, it can be assumed that in English the [wh] feature on C is strong, but in Japanese or Chinese it is weak (Haegeman, 1994). Concerning terminology, besides using the strength metaphor, relative $\mathrm{C}$ in various languages can be described as being specified (having a strong feature) or unspecified (having a weak feature) for the [wh] feature. Thus, it is claimed that the variability between languages in terms of whether there is overt movement of wh-operators or not is related to whether the predicative $\mathrm{C}$ is specified for the [wh] feature or not, which in turn determines the level at which wh-movement applies. In an attempt to make the subsequent discussion clearer, a language will be described and analyzed as a movement or non-movement language in terms of overt movement.

\section{B. RRC Formation in English}

In English, RRCs are complements to a noun in the main clause which is known as the head of the relative clause. This main noun is co-referential with a noun in the relative clause that is null in English. This null noun can be in subject, direct object, and object of a preposition or be part of a possessive construction (Hawkins, 2001). Examples in (8) illustrate object and object of preposition English RRCs which are the focus of this study.

(8) a. The house [which we bought_] is by the seaside.

b. The fiend [who I sent a letter to_] studies in Italy.

(Object)

(Object of a preposition)

In the above examples, the head noun and the relative clause are linked by a wh-word, but alternatively they can be linked by an overt ('that') or null (Ø) C (Hawkins, 2001):

(9) a. The house [that we bought_] is by the seaside.

b. The friend [I sent a letter to_] studies in Italy.

overt $C$

null $C$

In the case of object of preposition relatives, the preposition can be either stranded or pied-piped (Ross, 1967) along with the wh-word (Hawkins, 2001):

(10) a. The friend $\{$ who $\}$ I sent a letter to. \{that $\}$

preposition stranding

\footnotetext{
${ }^{1}$ The design of language provides a variety of symbolic systems, including the level of Logical Form (LF) which specifies aspects of meaning, insofar

as they are linguistically determined (Chomsky, 1995).
} 
b. The friend to whom I sent a letter. preposition pied-piping

A standard account of the structure of English RRCs is that they are CPs which are complements to the head noun (Hawkins, 2001). According to Chomsky (1986b) and subsequent work in syntax, RRC formation in English involves the movement of a wh-operator from a position in the embedded clause to Spec-CP position. The moved wh-phrase leaves a trace $(\boldsymbol{t})$ in the position in which it was generated. As Hawkins \& Chan (1997) have pointed out, since whoperators in English can be either overt ('who', 'which') or null (Op), an overt operator can only be combined with a null C (example 11a) while a null operator can be combined either with an overt ('that') or with a null C (Ø) (Examples $11 b, c)$.

(11) a. The boy [CP who Ø [IP I met $t]]$ will come to the party.

b. The boy [CP Op that [IP I met $t]]$ will come to the party.

c. The boy [CP Op $\emptyset[$ [IP I met $\boldsymbol{t}]]$ will come to the party.

In the case of preposition stranding, a wh-word is moved to Spec-CP position, while in the case of pied-piping a prepositional phrase containing the wh-word is moved (Hawkins, 2001):

(12) a. The friend [CP who Ø [IP I sent a letter to $t]]$.

b. The friend [CP to whom $\emptyset[$ [IP I sent a letter $\boldsymbol{t}]$ ].

However, a sentence like (13) would be unacceptable in English.

(13) *The boy [CP who that [IP I met $t]$ ] will come to the party.

According to Rizzi (1990), the distributional restrictions of operators and complementizers and, consequently, the ungrammaticality of sentences like (17) can be attributed to the feature specification of relative $\mathrm{C}$ and to a requirement for agreement among heads and specifiers. Rizzi introduced a feature system specifying the different kinds of $\mathrm{C}$ :

(14) a. +/-wh

b. +/-pred(icative)

(Rizzi, 1990, p. 67)

Based on this system, Rizzi proposed that relative clauses, which are clauses predicated of nouns, are headed by a [+ predicative] $\mathrm{C}$, while clauses which cannot be predicated are headed by a [-predicative] C. Rizzi argued that specifierhead agreement with respect to this feature is compulsory in the domain of $\mathrm{C}$ and suggested that a $\mathrm{C}$ specified for [+wh] can occur with a wh-operator in Spec-CP position, whereas a $\mathrm{C}$ specified for [-wh] cannot. In this sense, the [wh] feature of the relative $\mathrm{CP}$ forces an overt or null operator specified for the [wh] feature to move to Spec-CP position. According to Rizzi, this system of binary features can uniquely define specific morphemes belonging to $\mathrm{C}$. In relative clauses 'that' has the features [-wh] [+predicative], null $\mathrm{C}(\varnothing)$ has the features [+wh], [+predicative], overt whoperators have the features [+wh], [+predicative] and null operators have a [wh] feature, but with an unspecified value. Given that there is a requirement for specifier-head agreement in terms of the values of these features, a null $\mathrm{C}$ can occur both with an overt or null operator but an overt C ('that') can occur only with a null operator (Rizzi, 1990). Based on the above, (13) is ungrammatical because there is a clash between the feature values of 'who' and 'that' as presented below:

(15) The boy [CP who ${ }_{[+ \text {wh }]}$ that $_{[- \text {wh },+ \text { pred }]}\left[{ }_{\text {IP }}\right.$ I met $\left.\left.t\right]\right]$ will come to the party.

\section{RRC Formation in Greek}

In Greek, relativization is possible from the same range of NP positions as in English. This part will be devoted to the description of the structure of Greek object (O) and object of preposition/oblique object (OO) relatives which will be examined in the current experiment.

For the purposes of this work it will be assumed that Greek RRCs, like English RRCs are CPs which are complements to the head noun. In Greek, the morpheme which links the head noun and the relative clause can alternate

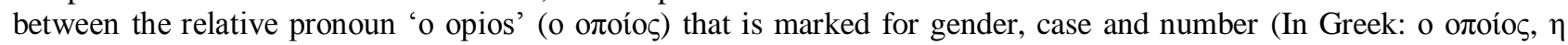
o $\pi$ oí $\alpha, \tau o$ o $\pi$ oío) and the relative pronoun 'pu' (In Greek: $\pi$ ov) that is not marked for gender, case or number (Tzartzanos, 1946).

Greek object relatives can be formulated in three ways:

(16) O mathitis pu ton katigorisan adika

The student that him blamed-3plural unjustly.

*The student that they blamed him unjustly.

(17) O mathitis pu katigorisan adika.

The student that blamed-3plural unjustly.

The student that they blamed unjustly.

(18) O mathitis ton opio katigorisan adika.

The student him-who blamed-3plural unjustly.

The student who(m) they blamed unjustly.

As these examples show, 'pu' can occur either with or without the resumptive pronoun 'ton', while 'o opios' cannot occur with a resumptive pronoun. It must be noted that in the example (18) 'ton' is not a resumptive pronoun but the article of the relative pronoun 'o opios'. Both the article and the pronoun are marked for case, gender and number and synthesize an agreeing form. Here, 'ton opio' is male in gender, accusative in case and singular in number. Additional evidence that Greek object RRCs can have a resumptive pronoun structure comes from Tsimpli (1997). In her 
investigation of resumptive strategies in SLA, Tsimpli assumes that Greek wh-questions optionally allow for a resumptive clitic pronoun co-indexed with the wh-phrase extracted from object position:

(19) Pjon eipes oti ton prosebalan xoris logo?

Whom said-2s that him-insulted-3p without reason

*Whom did you say that they insulted him without a reason?

(Tsimpli, 1997, p. 641)

Given that relative clauses are formulated with wh-movement, like wh-questions, the assumption about the existence of an optional resumptive pronoun can also be extended in Greek object RRCs. For the purposes of this discussion we will make the assumption that 'pu' and 'o opios' are respectively a neutral and an agreeing form of C heading the CP of the relative clause, as illustrated in $(20-22)^{2}$.

(20) O mathitis [CP pu [IP ton katigorisan adika]]. *The student that they blamed him unjustly.

(21) O mathitis [CP Op pu [IP katigorisan adika $t$ ]]. The student that they blamed unjustly.

(22) O mathitis [CP Op ton opio [IP katigorisan adika $t$ ]]. The student who(m) they blamed unjustly.

In Greek object of preposition relatives there are two possibilities:

(23) O sinadelfos pu i Anna malose mazi tu. The colleague that the Anna argued-3sing. with him.

* The colleague that Anna argued with him.

(24) O sinadelfos $\mathbf{m e}^{3}$ ton $^{4}$ opoio malose i Anna.

The colleague with him-who argued-3sing. the Anna.

The colleague with whom Anna argued.

Preposition stranding is impossible in Greek and so a relative clause like (25) would be ungrammatical in Greek:

(25) *O sinadelfos pou /o opoios i Anna malose mazi.

The colleague that /whom Anna argued with.

Following the same line of thought, the structure of the above sentences is the following:

(26) O sinadelfos [CP pu [IP i Anna malose mazi $\boldsymbol{t u}$ ]].

*The colleague that Anna argued with him.

(27) O sinadelfos [CP Op me ton opio [IP i Anna malose $t$ ]].

The colleague with whom Anna argued.

(28) *O sinadelfos [CP Op pu/o opios [IP i Anna malose mazi $\boldsymbol{t}]]$

The colleague that/who Anna argued with.

As the above examples indicate, in object and object of preposition relatives, Greek has an alternative resumptive structure which English lacks. Other languages that exhibit a resumptive pronoun strategy in RRCs and, crucially, lack of wh-movement are French (Haegeman, 1994) and Chinese (Hawkins \& Chan, 1997). Given that the use of a resumptive pronoun indicates a non-movement structure, it could be argued that when Greek uses resumptive pronouns in RRCs, no wh-operator movement takes place. This idea is reflected in the examples (20) and (26) where, unlike other examples of Greek RRCs, resumptive pronouns are used and null wh-operators are not moved to Spec-CP.

\section{A Parametric Difference between Greek and English}

As mentioned above, in object and object of preposition relatives Greek allows both a resumptive and a nonresumptive construction, while English disallows resumptive use. Since the existence of resumptive pronouns is taken as evidence of lack of wh-movement (Hawkins \& Chan, 1997; Haegeman, 1994), it can be argued that Greek instantiates both movement and non-movement strategies in RRC formation, while English represents only the movement option. But, what is it that forces overt movement in RRC formation? Hawkins \& Chan (1997) have suggested that operator movement is the result of a particular specification of the functional features of predicative $\mathrm{C}$. They have claimed that in the initial state of UG the functional category $\mathrm{C}$ is a cluster of unspecified parametric options including [predicative], [wh] and [Agr(eement)]. Based on the standard assumption that wh-operators in mature native grammars move to the Spec-CP position (Chomsky, 1995), Hawkins \& Chan argued that on exposure to L1 English, first language learners will acquire the fact that the [wh] feature under $\mathrm{C}$ is strong requiring that an operator (overt or null) move to the Spec-CP. While the overt ('that') and null (Ø) English complementizer, is specified for the [wh] feature, the Chinese predicative complementizer 'de' is minimally specified for predication and unspecified for [wh]. As a result, wh-operator movement is not possible in Chinese (Hawkins \& Chan, 1997). Since Greek instantiates both the possibility of movement and non-movement in the construction of RRCs, it appears to combine elements of English

\footnotetext{
${ }^{2}$ An investigation of the function of 'pu' and 'o opios' in the relative CP would go beyond the scope of the present discussion, thus, we make the aforementioned assumption but without any strong commitment to it.

${ }^{3}$ The Greek prepositions 'me' and 'mazi' have the same meaning ('with') and are usually used interchangeably. In the case of preposition pied-piping in oblique object relatives, the preposition 'me' seems to be preferred. Example (24) reflects this preference.

4 'ton' is not a RP, but the article of the relative pronoun 'o opoios'.
} 
and Chinese-type languages. Hawkins, (personal communication, 2001) has suggested that given the above observations, a possible assumption would be that there are two kinds of 'pu' in Greek: one specified and one unspecified for the [wh] feature. Shlonsky (1992) argues for a similar structure in Hebrew where there are to kinds of predicative 'še'. Apparently 'pu' has the same properties. When 'pu' is specified for the [wh] feature and the operator is an object operator, the form of 'pu' may change into an agreeing 'opios' form or remain unaltered (Examples 17, 18). However, as the example (24) illustrates, when the operator is an oblique object operator and 'pu' is specified for the [wh] feature, then it is required that the form of 'pu' changes into an agreeing 'opios' form. So, it seems that the possibility of two forms when $\mathrm{C}$ is specified for [wh] can exist only when the operator is an object operator. It could be hypothesized that the possibility of two forms is related to the presence or absence of preposition. In Greek object of preposition relatives where ' $\mathrm{pu}$ ' is specified for [wh], the preposition is pied-piped along with the operator, since preposition stranding is impossible in Greek (see example 25). In preposition pied-piping structures, an agreeing form of 'pu' is required.

\section{PRevious L2 Studies}

Most L2 studies report that native and non-native sensitivity to subjacency violations differ.

White, Travis \& McLachlan in 1992 tested high and low intermediate Malagasy learners of English by means of a judgement and a question formation task. Malagasy differs from English both in the domains out of which wh-elements can be extracted and in the nature of the position from which the phrase is extracted (gaps). In terms of domains, neither language allows extraction out of a complex NPs or adjuncts. English allows extraction out of object NPs and CPs, while Malagasy only permits extraction out of subject CPs. In terms of gaps, while Malagasy allows only subjects to be extracted, English permits subjects and non-subjects to move. However, subject wh-movement is restricted in order to avoid that-trace effects. White, Travis \& McLachlan found that Malagasy speakers of both levels are familiar with the domains and gaps in English wh-movement: they rejected extraction out of complex NPs, adjuncts and NP subjects and they accepted movement out of CP objects. Additionally, learners allowed wh-movement both from subject and object position. White, Travis \& McLachlan interpreted these results as evidence of parameter resetting in adult L2. Martohardjono \& Gair targeting L2 movement operations studied in 1993 the acquisition of English relative clauses and topic constructions by Indonesian learners. Indonesian was assumed to instantiate both movement and non-movement operations in topicalization. Conversely, no movement is involved in relativization. Martohardjono \& Gair reported a development in L2 performance with advanced Indonesian learners faring more successfully in rejecting subjacency violations than intermediate learners. Interestingly, it was found that in topic constructions both learner groups perform strikingly well. The researchers claimed that the possibility of movement in L1 Indonesian facilitated the acquisition of English topic constructions, despite the existence of a non-movement alternative construction in L1.

More recently, Hawkins \& Chan (1997) studied the acceptability of ungrammatical English RRCs in the L2 grammars of Chinese and French elementary, beginner and advanced L2 learners. They assumed that the existence or not of wh-movement in RRC formation reflects a parametric difference between L1 and L2: while the predicative C in English is specified for the [wh] feature which triggers operator movement, the predicative $\mathrm{C}$ in Chinese is not. Hawkins \& Chan's results showed that Chinese learners were significantly less accurate in rejecting and correcting ungrammatical RRCs than age and proficiency-matched French learners. However, the fact that Chinese learner performance on ungrammatical CP constructions improves with increasing proficiency was interpreted by the researchers as an indication of their ability to acquire the surface morphophonological properties of the English predicative C. Moreover it was found that, Chinese learners were able to progressively acquire the [CP...gap] pattern of English RRCs, even in cases where a resumptive pronoun is allowed or required in their L1. Crucially though, statistical analyses of items displaying subjacency violations (wh-island and complex NP) have revealed that advanced Chinese learners were significantly less accurate in detecting wh-island violations than French learners and English controls. Hawkins \& Chan's explanation of these results was that although advanced Chinese subjects had acquired the surface [CP...gap] structure of English RRCs, they were unable to acquire the parametric option of wh-operator movement involved in English RRCs. On the background of theses results, Hawkins \& Chan proposed the Failed Functional Features Hypothesis which constitutes a syntactic characterization of UG availability in SLA: abstract syntactic features (i.e. [wh] on the relative C) which are associated with parameters remain inaccessible in adult L2 acquisition while UG principles continue to guide the process. The L2 acquisition of wh-movement was also investigated in Wong \& Hawkins' study in 2000 on English argument questions. The L2 group consisted speakers of Malay, a language which exhibits wh-movement in the relevant constructions but only when the argument is in subject position. Wong \& Hawkins reported no significant differences between L2 learners and native speakers in items involving movement of matrix objects as well as of embedded subjects and objects, which, according to Wong \& Hawkins indicates that advanced learners are able to acquire wh-movement from positions not found in their L1. However, Wong \& Hawkins detected a problem with embedded clauses introduced by 'that' since Malay speakers displayed target deviant performance in that they accepted ungrammatical subject extraction items and rejected grammatical object extraction ones. Thus, Wong \& Hawkins argued that even though advanced Malay learners were able to extend wh-movement to positions not found in Malay they failed to acquire the feature specification of the English $\mathrm{C}$ and therefore reset the parameter from the L1 to the L2 value. Finally, in a more recent study Kiss-Gulyás (2004) examined the acquisition of 
English RRCs by Hungarian learners of English. In Hungarian the relative C is [+pred], [+wh] but 'that' is disallowed in RRC formation. Kiss-Gulyas' findings are in line with Hawkins and Chan's data, since it is reported that Hungarian learners of all levels and, crucially, of near-native proficiency were not able to fully acquire the morphophonological realization of the English [+pred] C. Kiss-Gulyás claimed that the attested persistent inconsistency in L2 performance reveals that $\mathrm{L} 1$ parametric options cannot be reset as regards the function of $\mathrm{C}$ in English.

\section{RESEARCH HYPOTHESIS}

On the assumption that UG is in some way accessible to L2 learners (i.e. at least through its principles) making available the $[\mathrm{wh}]$ feature, whether languages specify $\mathrm{C}$ for that feature or not is subject to parameter setting (Hawkins, 2001). Regarding the issue of parameter resetting in adult L2 acquisition, i.e. the possibility of acquiring in non-primary L2 development abstract syntactic features which differ between L1 and L2, this paper will adopt a formal features deficit account. In particular, the prediction is that since L1 Greek and L2 English instantiate syntactically different options regarding RRC formation, the Greek learners of the experiment will fail to acquire the feature specification of the English relative $\mathrm{C}$ even at advanced stages, although they may superficially appear to have acquired the [CP...gap] structure of English.

\section{THE EXPERIMENT}

\section{A. Method}

\section{Participants}

The experimental group of this study consisted of 10 adult Greek speakers (age range: 22-25) who held the Cambridge Proficiency in English and were thus considered advanced learners. Greek learners had been studying English for an average of 9.9 years at the time the test, and were exposed to the language after the age of 9 . Therefore, it can be safely argued that they are adult learners of the language. All participants were full-time postgraduate students at the University of Essex and they had a 10-month exposure to English in a naturalistic setting. None of the non-native participants was studying linguistics either at undergraduate or postgraduate level. Apart from Greek learners, 10 native speakers of English (age range: 20-27) were used as a control group. Data from the English natives was used to confirm the administrator's judgements about which sentences are acceptable in English and which are not. Eight participants of the control group were postgraduate students and two were undergraduate students at the University of Essex.

\section{Materials}

To elicit data a Grammaticality Judgement (GJ) task was designed. A GJ task was chosen to other types of data collection because relative clauses constitute complex structures which are not frequent in L2 spontaneous production or even in the guided production of learners (see White, 1989; Wong \& Hawkins, 2000). In an attempt to balance the complexity of the targeted structure, care was taken to ensure that the sentences of the test were as natural as possible and without too high lexis. The task consisted of 30 test items and 12 distractor items. From the test items, 20 were ungrammatical and 10 grammatical $^{5}$. Ungrammatical items aimed to test the acceptability of structures which induce movement violations in the L2, while grammatical items aimed at to examine whether learners have acquired movement from object and object of preposition NP positions targeted by this study. Only subjects who were $90 \%$ accurate in this within-GJ syntax test judging as probably or definitely acceptable 9 out of the 10 grammatical sentences were included in final the experiment ${ }^{6}$. Grammaticality also cut across the distractor items resulting in 6 grammatical and 6 ungrammatical sentences. There were also two introductory practice items which, like the distractor sentences, were not subjected to analysis.

The variables used in the design of the grammatical items were movement position, i.e. object and object of preposition NP, and operator type, i.e. overt or null (OoP, NoP respectively). Four out of the ten items were instances of object relatives, while six were instances of object of preposition relatives. In the object relative type, half of the sentences involved overt operators and half null. In the object of preposition type, two involved null operators, while the remaining four overt operators. In the overt operator subtype, half of the items were instances of preposition stranding (PrS) (a property not available in L1 Greek) while the other half were instances of preposition pied-piping (PrP) (the only option in L1 Greek). Sentences in (33) provide examples of grammatical Object RRCs, while sentences in (34) exemplify grammatical OO RRCs:

(33) a. The friend who(m) Vicky will visit lives in London

b. Have you read the latest book that Isabel Alliente has written

(34) a. The salary which he had to live on was extremely poor

b. The man with whom they have been talking is my supervisor

c. The new job that he has applied for is very well paid

(O RRC, OoP)

(O RRC, NoP)

(OO RRC, OoP, PrS)

(OO RRC, OoP, PrP)

(OO RRC, NoP)

\footnotetext{
${ }^{5}$ The decision to include fewer grammatical items than ungrammatical reflects the concern of not designing a too big test instrument which would be difficult to complete.

${ }^{6}$ This procedure excluded four participants from the experimental group, the result being a group of 10 learners.
} 
The variables used in the design of the ungrammatical items were movement position, i.e. object and object of preposition NP, subjacency violation type, namely wh-islands and complex NPs, and Resumptive Pronoun (RP) existence or not. From the twenty items, eight were object relatives and twelve object of preposition relatives. In each type, half of the sentences represented wh-island violations and the other half complex NP violations. Additionally in the object RRCs, half of the items of the wh-island violation type also instantiated resumptive pronoun use, while in the other half no resumptive pronouns were used. The same distinction was found in the complex NP violation type. In the object of preposition RRCs across violation types, two sentences featured resumptive pronoun use, while four did not. Sentences (35-36) are examples of ungrammatical object and object of preposition RRCs respectively:

(35) a. * This is the employee whom Anna heard the rumor that the boss will promote (O RRC, Compl. DP viol.)

b. * I've head the song that the band asked their manager when they will record it (O RRC, wh-isl. viol., PR)

(36) a. * I read the provisions of the contract that there is a good possibility that their lawyer will object to them.

(OO RRC, Compl. DP viol., PR)

b. * I've just met the colleague who(m) Michael asked me when Jenny argued with

(OO RRCs, wh-isl. viol.)

Procedure

Before proceeding to the GJ task, participants read written instructions in their native language. They were asked to decide on the (un)acceptability ${ }^{7}$ of a sentence as quickly as they could and were not allowed to go back and change any of their answers. When participants judged a sentence as unacceptable, they were asked to underline the part of it that was causing the ungrammaticality. Responses which attributed the ungrammaticality of an item to the wrong factors were excluded from the analysis. Participants had to indicate their judgements using a five-point Likert type scale from -2 to +2 as follows: -2 would be given to a definitely unacceptable sentence, +2 to a definitely acceptable one and 0 if they thought that a sentence was neither acceptable or unacceptable, or in other words, had equal chances of being acceptable or unacceptable realizing an 'in-between' and not a 'don't know' option (Sorace, 1996, p. 37). Note that, according to these instructions, the ' 0 ' category was not used to encode pure indeterminacy and, therefore, the items judged in this way were not eliminated in the statistical analysis. Participants were also given two more choices encoding (un)acceptability: -1 and +1 : participants were instructed that they ought to use them when they were not as certain about the ( un)acceptability of a sentence as they were when they used the -2 and +2 choices. In other words, the difference between the extremes of the scale $(-2,+2)$ and the intermediate categories $(-1+1)$ is whether the participants judge a sentence as definitely or probably (un)acceptable. Consequently, in data analysis and in the interpretation of the results the two points on the negative and positive part of the scale were not conflated into one choice, a decision which together with the use and interpretation of the ' 0 ' category differentiates this experiment from much of L2 acquisition research regarding methodology. For statistical purposes and in order to capture the aforementioned contrasts, during data inputting we matched the -2 to +2 scale to a five-point positive scale ranging from 0 to 4 . The advantage of this scale is that for both acceptable and unacceptable items, the higher the score, the better the response regarding both accuracy and certainty. Table 1 presents the interpretation for each category in the two 5-point scales:

TABLE I.

INTERPRETATION OF TEST CATEGORIES

\begin{tabular}{|c|c|c|c|}
\hline Unacceptable & Acceptable & -2 to +2 scale & 0 to 4 scale \\
\hline definitely unacceptable & definitely acceptable & $-2 /+2$ & 4 \\
\hline probably unacceptable & probably acceptable & $-1 /+1$ & 3 \\
\hline Neither acceptable not unacceptable & & 0 & 2 \\
\hline probably acceptable & probably unacceptable & $+1 /-1$ & 1 \\
\hline definitely acceptable & definitely unacceptable & $+2 /-2$ & 0 \\
\hline
\end{tabular}

\section{Analysis}

Significant and non-significant differences in between-group comparisons (i.e. Greek learners vs. English controls) were assessed be means of independent samples t-tests. This analysis was preferred to one-way ANOVA which is used in many similar experiments since the participant groups of this experiment were two. Although it is not impossible to analyze the above results with one-way ANOVA (such analysis was also attempted and yielded similar results), independent samples t-tests constitute a more accurate and suitable procedure for the present data (Scholfield, 2001). Significant and non-significant differences in within-group comparisons regarding the experimental conditions as these were outlined in the Materials Section were assessed be means of paired samples t-tests.

\section{B. Results}

Results will be presented first for object relatives and then for object of preposition relatives. For each type, betweengroup comparisons will ne presented first, and within-group comparisons will follow.

Starting with object relatives, Fig. 1 presents group accuracy rates in the ungrammatical items of the test:

\footnotetext{
${ }^{7}$ Note that the term '(un)acceptability' was used instead of '(un)grammaticality' since the latter could discourage participants from taking part in the experiment as they may sound too 'formal' or academically oriented. In the presentation and interpretation of the results however the terms will be used interchangeably. The task was administrated in groups of two or three each time and the administrator was present during this process.
} 


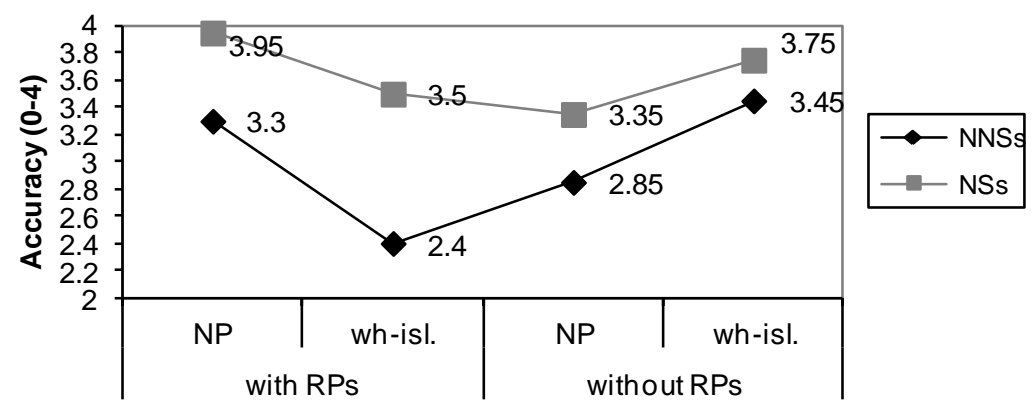

Figure 1. Accuracy in Ungrammatical Object RRCs

Regarding between-group comparisons, independent samples t-test conducted on the rates of Fig. 1 yielded significant differences between the learner and the control group in both ungrammatical structures involving RPs. Greek learners fared significantly less accurately in rejecting ungrammatical object RRCs violating the wh-island and the complex NP constraint in the presence of RPs ( $p=0.015$ and $p=0.05$ respectively). Conversely, in the items where no RPs were used, the learner groups were as accurate as the English controls in judging the sentences as ungrammatical (both ps > 0.05).

Turning next to within-group comparisons, paired-samples t-test have revealed that Greek learners accepted significantly more ungrammatical items with RRs violating the wh-island constraint than ungrammatical items without RPs inducing the same violation ( $p=0.021$ ). As for the control group, the analysis has returned a significant difference in the rejection rates of items violating the complex NP constraint: items with RPs were judged more accurately than items with RPs $(p=0.037)$.

Fig. 2 that follows presents participant scores in grammatical object relatives:

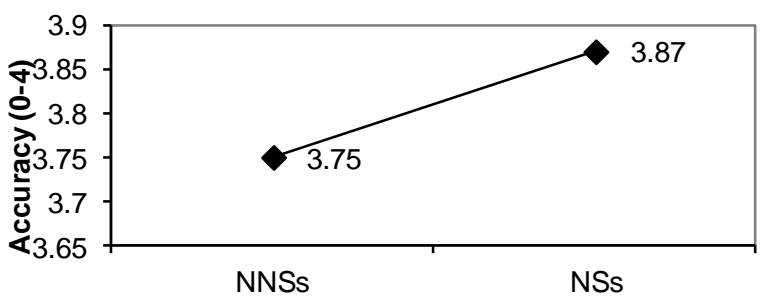

Figure 2. Accuracy in Grammatical Object RRCs

Independent samples t-test conducted on the scores above showed that the performance of the L2 group was not significantly less accurate than the performance of the control group.

Next, the analysis for the object of preposition relatives will be presented. Fig. 3 provides the descriptive statistics for these items.

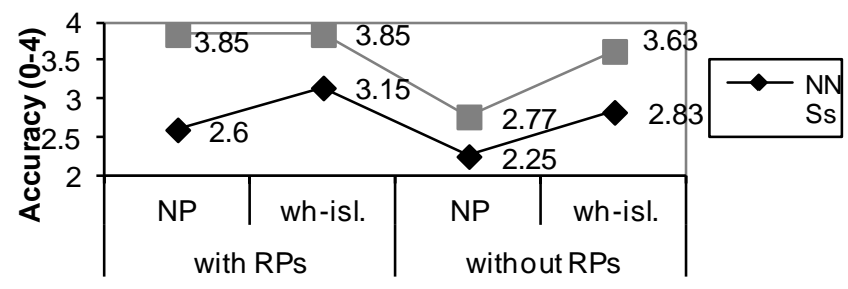

Figure 3. Accuracy in Ungrammatical Object of Preposition RRCs

With respect to between-group comparisons, independent samples t-test conducted on the rates of Fig. 3 returned significant differences between the Greek learner and the English control group in the three out of the four structures involved. In particular non-native speakers achieved significantly lower rejection scores than the natives in object of preposition RRCs with RPs violating the complex NP and the wh-island constraint, as well as in items without RPs inducing wh-island violations ( $p=0.004, p=0.004$ and $p=0.031$ respectively).

Within-group group comparisons conducted through paired-samples t-test have shown no significant differences in the Greek learner group (all ps > 0.05). In the control group on the other hand, it was found that as in the object relatives, the English natives were more accurate in rejecting complex NP violation items with RPs than without RPs $(p=0.001)$. 
Finally, Fig. 4 presents group rates in grammatical object of preposition relatives:

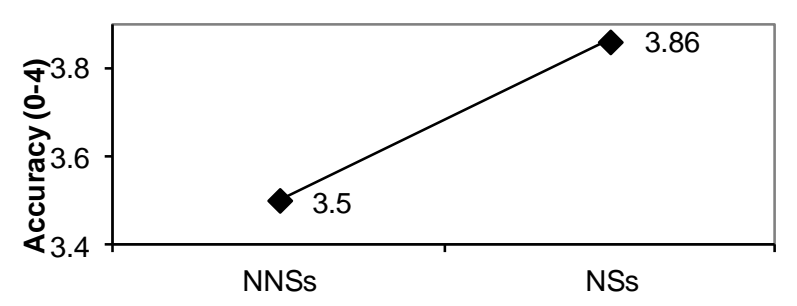

Figure 4. Accuracy in Grammatical Object of Preposition RRCs

The statistical analysis on the scores of Fig. 4 revealed that Greek learners were significantly less successful than the English controls in accepting grammatical English object of preposition relatives $(\mathrm{p}=0.027)$.

\section{DISCUSSION}

The discussion presented here focuses on the results obtained on English RRC L2 acquisition. Adopting a formal features deficit account the prediction was that since L1 Greek and L2 English represent different parametric options as regards RRC formation, Greek learners will encounter problems in acquiring the feature specification of the English relative $\mathrm{C}$ although superficially they may appear to have acquired the [CP...gap] structure of English RRCs.

Data on grammatical set of the test has revealed significant between-group differences only in object of preposition relatives with the native group accepting them at a higher rate than the non-native group. However, recall that Greek speakers who were finally included in the experiment had correctly accepted 9 of the 10 grammatical test items and passed the within-GJ task syntax test. Thus, it can be argued that the difference found in this case may not be indicative of the fact that Greek learners have not acquired the [CP...gap] structure of object of preposition RRCs, but could be related to the contrast of object and object of preposition relatives as regards the complexity of the extraction mechanism involved. Wolfe-Quintero (1992) has argued that concerning English RRCs, L2 learners seem to follow an implicationally related acquisition order. From extraction from Verb Phrases (VPs) (object RRCs), L2 learners move to extraction from Prepositional Phrases (PPs) in VPs (object of preposition RRCs). Other studies (Hyltenstam, 1984; Tarallo \& Myhill, 1983) have also suggested that the relativization of NP positions lower in the Noun Phrase Accessibility Hierarchy ${ }^{8}$ (NPAH) (object of preposition) seems to be more problematic for L2 learners than the relativization of NP positions higher in the NPAH (direct object). Therefore, not surprisingly, Greek learner performance in object of preposition RRCs is not as successful as English native performance. However, given the learners' overall successful performance in the within-syntax GJ test, this finding does not necessarily show that they have not acquired the structure of English RRCs. Additionally, in the object RRC they were as accurate as the English controls. Based on the above, it could be claimed that advanced Greek learners have acquired the [CP....gap] structure of English object and object of preposition RRCs.

Turning next to the ungrammatical set, the analysis has shown that Greek learners are significantly less accurate than the English controls in nearly all the conditions of the task: both types of subjacency violations (i.e. wh-island and complex NP constraint) gave rise to learner performance which deviated from the native norm especially when resumptive pronouns were used. Assuming the presence of resumptive pronouns suggests lack of wh-movement, learner performance in resumptive pronoun structures not only shows the transfer of an L1 property of RRC formation in L2 but also constitutes additional evidence that no movement is involved in advanced Greek learner L2 representations of RRCs. Within-group comparisons on non-native data have lent additional support to the claim that resumptive pronoun presence is related to lower accuracy rates: object relatives with resumptive pronouns were judged as more acceptable than object relatives without resumptive pronouns across both subjacency violation types. Conversely, in native data, resumptive pronouns had the opposite effect since they enhanced the ungrammaticality effect inducing higher rejection scores. These findings add support to the claim that the mental representations of wh-movement in RRC structures is different for the natives and the non-natives of this experiment. What is interesting in the case of L2 learners of a language like Greek is that, according to the theoretical assumptions on RRC formation presented in Section II, their L1 instantiates both movement and non-movement structures having two kinds of relative complementizers, one specified for the [wh] feature and one not. The obtained results indicate that the existence of a $\mathrm{C}$ unspecified for [wh] and, consequently, the possibility of a resumptive structure in L1 RRCs may prevent the acquisition of L2 wh-movement structures even when wh-movement exists as a possibility in L1. This finding contradicts Martohardjono \& Gair's (1993) data on the acquisition of English topic constructions by speakers of Indonesian, a language which unlike L2 English exhibits both movement and non-movement possibilities in topicalization. Martohardjono \& Gair claimed that

\footnotetext{
${ }^{8}$ According to NPAH, accessibility in relative clause formation of certain NPs is can be represented by the following: Accessibility Hierarchy Subject>Direct Object>Indirect Object >Object of Comparison (Comrie \& Keenan, 1979)
} 
the L1-L2 parallelism in terms of movement facilitated the acquisition of the L2 relevant structure. However, the performance of the Greek learners of this study has shown that they may be unable to reset the parametric option in $\mathrm{C}$ and thus allow for wh-operator movement, despite the fact that their L1 realizes a wh-movement structure, albeit does not require it. This is a finding that strongly supports the impossibility of parameter resetting in postchildhood L2 acquisition. According to the present experiment, problems in acquiring the parametric L2 value are noted not only when the L1 does not instantiate the L2 value, but also, as in the case of Greek, when the L1 does not instantiate only the L2 value. The obtained results also contradict the findings of White, Travis \& McLachlan's study (1992) based on which the researchers propose that parameter resetting in L2 acquisition is feasible. The present findings are compatible with no parameter-resetting views on RRC acquisition like Hawkins \& Chan's (1997) and Kiss-Gulyas' (2004). More specifically, it appears that the predictions of Hawkins \& Chan's (1997) Failed Functional Features Hypothesis can be extended to a language like Greek which combines elements of Chinese and English-type languages instantiating partial movement in the sense that both possibilities of movement and non-movement exist.

Based on the above, and despite any methodological limitations inherent in any language acquisition experiment, it can be argued that the prediction about the inaccessibility of abstract syntactic features in post-puberty L2 acquisition is verified by the current experiment.

\section{CONCLUSION}

The present work has attempted to present a formal description of the differences between Greek and English RRCs. To this end, it was assumed that Greek instantiates both movement and non-movement possibilities in RRCs formation, while English exhibits only movement structures. It was hypothesized that these differences can be explained in terms of parametric variation associated with a divergence as regards abstract syntactic feature specification. On this basis, an investigation of whether adult Greek learners of English can reset the parameter from the L1 to the L2 value and acquire the feature specification of the English $\mathrm{C}$ was undertaken. The aim was to examine the issue of persistent optionality in the L2 acquisition of complex structures like RRCs. The empirical study presented here has provided evidence in support of formal features deficit accounts like the ones put forward by Tsimpli \& Smith (1991), Smith \& Tsimpli (1995) as well as by Hawkins \& Chan (1997) which maintain that ultimate attainment of syntactic structures representing different parametric options between L1 and L2 is problematic. Parametric choices and the related abstract syntactic features are subject to maturational effects and are thus unavailable to the L2 learner as means of analyzing the L2 input (Tsimpli \& Mastropavlou, 2007; Prentza \& Tsimpli, in press). This results to L2 grammars that may superficially approximate the native norm but are essentially different with respect to abstract feature specification. Finally, with respect to the more practical aspect of language teaching, this paper, besides offering a detailed account of RRC formation in English and how this differs from a number of languages and, essentially, from Greek, would also like to propose that although the theory predicts prolonged acquisitional problems in areas where L1 and L2 syntax differ, conscious effort from the teacher and the learner could greatly improve L2 performance provided that foreign language teachers fully understand all the aspects of the phenomena they are to teach.

\section{REFERENCES}

[1] Beck, M. L. (1998). L2 acquisition and obligatory head movement: English-speaking learners of German and the local impairment hypothesis. Studies in Second Language Acquisition 20, 311-348.

[2] Chomsky, N. (1981). Lectures on Government and Binding. Dordrecht: Foris.

[3] Chomsky, N. (1986a). Knowledge of Language. New York: Praeger.

[4] Chomsky, N. (1986b). Barriers. Cambridge, Mass.: MIT Press.

[5] Chomsky, N. (1995). The Minimalist Program. Cambridge, Mass.: MIT Press.

[6] Comrie, B \& E.L. Keenan. (1979). Noun phrase accessibility revisited. Language 55, 646-664.

[7] Fabb, N. (1990). The difference between English restrictive and nonrestrictive relative clauses. Journal of Linguistics 26, 58-78.

[8] Haegeman, L. \& J. Gueron. (1999). English Grammar: A generative Perspective. Oxford: Blackwell.

[9] Hawkins, R. (2001). Second Language Syntax: A Generative Introduction. Oxford: Blackwell.

[10] Hawkins, R. \& C. Chan. (1997). The partial availability of Universal Grammar in second language acquisition: the 'failed functional features hypothesis' Second Language Research 13, 187-226.

[11] Hawkins, R. and H. Hattori. (2006). Interpretation of English multiple wh-questions by Japanese speakers: a missing uninterpretable feature. Second Language Research 22, 269-301.

[12] Huddleston, R. (1993). Introduction to the Grammar of English. ( $5^{\text {th }}$ edn.) Cambridge: Cambridge University Press.

[13] Hyltenstam, K. (1984). The Use of Typological Markedness Conditions as Predictors in Second Language Acquisition: The Case of Pronominal Copies in Relative Clauses. In R. Andersen (ed.), Second languages: a cross-linguistic perspective. Rowley, Mass.: Newbury House, 41-58.

[14] Kiss-Gylyas, J. (2004). The acquisition of English Restrictive Relative Clauses by Hungarian learners of English. Budapest: Akadémiai Kiádo.

[15] Martohardjono, G., \& Gair, J. (1993). Apparent UG inaccessibility in second language acquisition: misapplied principles or principled misapplications? In F. Eckman (ed.), Confluence: Linguistics, L2 acquisition and speech pathology. Amsterdam: John Benjamins, 79-103.

[16] Prentza, A. and I. M. Tsimpli (in press). The interpretability of features in second language acquisition: evidence from null and postverbal subjects in L2 English. Journal of Greek Linguistics. 
[17] Rizzi, L. (1982). Issues in Italian Syntax. Dordecht: Foris.

[18] Rizzi, L. (1990). Relativized Minimality. Cambridge Mass.: MIT Press.

[19] Ross, J. (1967). Contraints on variables in Syntax. Unpublished Doctoral Dissertation. MIT.

[20] Scholfield, P. (2001). Unpublished class notes, University of Essex, 2001

[21] Shlonsky, U. (1992). Resumptive pronouns as a last resort. Linguistic Inquiry 23, 443-68.

[22] Smith, N. \& I.M. Tsimpli (1995). The mind of a savant. Language Learning and Modularity. Oxford: Blackwell.

[23] Sorace, A. (1996). The use of Acceptability Judgements in Second Language Research. In Ritchie, W. \& T. Bahtia (Eds.), Handbook of Second Language Acquisition. San Diego: Academic Press, 375-405.

[24] Tarallo, F. \& J. Myhill (1983). Interference and natural language processing in second language acquisition. Language Learning 33, 55-76.

[25] Tsimpli, I. M. (1997). Resumptive features and minimalism: evidence from second language acquisition. Proceedings of the $21^{s t}$ Annual Boston University Conference on Language development. Somerville, Mass.: Cascadilla Press (vol. 1), 257-268.

[26] Tsimpli, I. M. \& M. Dimitrakopoulou. (2007). The Interpretability Hypothesis: evidence from wh-interrogatives in second language acquisition. Second Language Research 23, 215-242.

[27] Tsimpli, I.M. \& M. Mastropavlou. (2007). Feature interpretability in L2 acquisition and SLI: Greek clitics and determiners. In J. Liceras, H. Zobl \& H. Goodluck (eds.), The role of formal features in second language acquisition. Mahwah, NJ: Lawrence Erlbaum, 143-183.

[28] Tsimpli, I. M, \& A. Roussou. (1991). Parameter resetting in L2? UCL Working Papers in Linguistics 3, 149-69.

[29] Tzartzanos, A. (1996). The syntax of Modern Greek (2 $2^{\text {nd }}$ edn.). Thessaloniki: Kyriakidis

[30] White, L. (1989). Universal Grammar and Second Language Acquisition. Amsterdam: John Benjamins.

[31] White, L., Travis, L. \& A. McLachlan. (1992). The Acquisition of Wh-Question formation by Malagasy learners of English: Evidence for Universal Grammar. Canadian Journal of Linguistics 37, 341-368.

[32] Wolfe-Quintero, K. (1992). Learnability and the acquisition of extraction in the relative clauses and wh-questions. Studies in Second Language Acquisition 14, 39-70.

[33] Wong, B. \& R. Hawkins. (2000). An unexpected wh-phrase extraction asymmetry in the advanced L2 English of Malay speakers. Working Papers in Linguistics (Special issue, Proceedings of GASLA 4) 4, 226-241.

Alexandra I. Prentza was born in Ioannina, Greece in 1978. She holds a BA in English Language and Literature from the Aristotle University of Thessaloniki, Greece (2000), an MA in Applied Linguistics from the University of Essex, United Kingdom (2001) and a Ph.D in Linguistics from the Aristotle University of Thessaloniki, Greece (2010). In her doctoral dissertation she studied feature interpretability in relation to the Null Subject Parameter in Second Language Acquisition.

For the last four years she has been teaching English as a foreign language to the primary school of Cross-Cultural education in Ioannina. The majority of her pupils are bilingual and trilingual. From 2001 up to 2005 she has taught English in the secondary and tertiary education as well. She has also taught language development courses in the Department of Speech Therapy in the Technological Institute of Epirus from 2007 up to 2011. She has participated as instructor in teacher training programs of the Greek Ministry of Education. She has published articles on second language syntax, bilingualism and Modern Greek syntax. 